\title{
Women in the midluteal phase of the menstrual cycle have difficulty suppressing the processing of negative emotional stimuli: An event-related potential study
}

\author{
Bethany R. Lusk ${ }^{1}$ • Andrea R. Carr ${ }^{2}$ • Valerie A. Ranson ${ }^{1}$ • Kim L. Felmingham ${ }^{3}$
}

Published online: 5 June 2017

(C) Psychonomic Society, Inc. 2017

\begin{abstract}
Emotion regulation deficits have been implicated in anxiety and depressive disorders, and these internalising disorders are more prevalent in women than men. Few electrophysiological studies have investigated sex differences in emotional reactivity and emotion regulation controlling for menstrual phase. Event-related potentials (ERPs) were recorded from 28 early follicular women, 29 midluteal women, and 27 men who completed an emotion regulation task. A novel finding of increased N2 amplitude during suppression was found for midluteal women compared with men. These findings suggest midluteal women may be significantly less able to suppress cortical processing of negative stimuli compared to men. This ERP finding was complemented by behavioral ratings data which revealed that while both early follicular and midluteal women reported more distress than men, midluteal women also reported greater effort when suppressing their responses than men. P1 and N1 components were increased
\end{abstract}

\section{Highlights}

- Novel finding of suppression effect during conscious N2 processing showing midluteal women have poorer suppression ability than men.

- When suppressing their emotional responses, early follicular and midluteal women reported greater emotional distress than men, and midluteal women also reported greater effort relative to men.

- Late conscious emotion regulation processing was not impacted by sex or menstrual phase.

Bethany R. Lusk

brlusk@utas.edu.au

1 School of Medicine (Division of Psychology), University of Tasmania, Private Bag 30, Hobart, Tasmania 7001, Australia

2 Division of the Deputy Vice-Chancellor (Students and Education), University of Tasmania, Hobart, Tasmania 7001, Australia

3 School of Psychological Sciences, University of Melbourne, Melbourne, Victoria 3010, Australia in midluteal women compared to men regardless of instructional set, suggesting greater early attentional processing. No sex or menstrual phase differences were apparent in P3 or LPP. This study underscores the importance of considering menstrual phase when examining sex differences in the cortical processing of emotion regulation and demonstrates that midluteal women may have deficits in down-regulating their neural and behavioural responses.

Keywords Event-related potential $\cdot$ Attention bias $\cdot$ Sex differences $\cdot$ Emotion regulation $\cdot$ Menstrual cycle $\cdot$ Midluteal phase

Anxiety and depressive disorders occur at approximately twice the rate in women compared to men (Kessler, Chiu, Demler, \& Walters, 2005; Kessler et al., 1994; McLean, Asnaani, Litz, \& Hofmann, 2011), but the mechanisms underlying the higher female prevalence rates for these internalising disorders is unclear. Proposed mechanisms that underlie anxiety and depressive disorders include affective reactivity and deficits in the regulation of negative emotional states (e.g., Cisler \& Koster, 2010; Etkin, 2009; Farb, Anderson, \& Segal, 2012; Price \& Drevets, 2012; Waugh, Hamilton, Chen, Joormann, \& Gotlib, 2012). Emotion regulation processing involves both early emotional reactivity and later emotion regulation components (Gross, Sheppes, \& Urry, 2011). Early emotional reactivity refers to the preconscious processing and automatic allocation of attention to emotionally salient stimuli (Lithari et al., 2010). Early emotional reactivity precedes and influences later emotion regulation, which involves the conscious regulation of one's experience of emotionally pertinent stimuli (Gross et al., 2011). Emotional response to emotion-inducing stimuli may be increased, 
decreased, or maintained following the use of emotion regulation strategies (Gross, 2007; Gross et al., 2011).

In line with the process model of emotion regulation (PMER; Gross \& Thompson, 2007), two primary emotion regulation strategies used by individuals with anxiety and depression for decreasing emotional responses are reappraisal and suppression. Reappraisal is an early antecedent-focused strategy involving cognitive modification of emotional responses by consciously altering the meaning of an emotion inducing stimulus to decrease its emotional influence (Goldin, McRae, Ramel, \& Gross, 2008). Suppression is a later response-focused strategy, which involves behavioral strategies for the reduction of emotionally expressive behavior by concealing and avoiding emotions as they arise (Gross \& John, 2003; Hajcak \& Nieuwenhuis, 2006). The emotion literature demonstrates that suppression is typically a less adaptive strategy than reappraisal, as it can lead to a paradoxical increase in negative affect and physiological arousal compared to reappraisal, which generally leads to decreased psychological distress and physiological arousal (Hofmann, Sawyer, Fang, \& Asnaani, 2012).

Functional magnetic resonance imaging (fMRI) methodology has been employed to map the neural networks of reappraisal and suppression by measuring cortical and subcortical activation during emotion regulation tasks. Goldin et al. (2008) compared the neural effects of reappraisal and suppression to unpleasant films using fMRI and found that the reappraisal instruction elicited early prefrontal cortical activation, decreased amygdala and insular activity, and decreased negative emotion experience, whereas suppression elicited late prefrontal cortex activity and increased amygdala and insular response (Goldin et al., 2008).

While these findings are in line with the predictions of the PMER, the Goldin et al. (2008) study is limited by the failure to control for sex differences. fMRI studies examining reappraisal have produced conflicting results. McRae, Ochsner, Mauss, Gabrieli, and Gross (2008) found that men have reduced amygdala activity during emotion regulation compared to women, suggesting a greater capacity to regulate unpleasant emotional responses relative to women. Coupled with decreased amygdala activity, men also showed less activation of prefrontal regulatory networks involved in emotion regulation than women, which McRae et al. (2008) interpreted as reflecting more efficient emotion regulation processing in men relative to women. In contrast, Domes et al. (2010) found that men had greater prefrontal region activation than women, with no sex differences in amygdala activation. Inconsistencies in neuroimaging findings may be related to the poor temporal resolution of fMRI, which limits the delineation of precise temporal processes associated with early emotional reactivity and later emotion regulation. Discrepancies between previous fMRI studies may also be explained by the failure of these studies to control for the impact of menstrual cycle.
The high temporal resolution of event-related potentials (ERPs) compared to neuroimaging techniques allows the delineation of sex differences in early emotional reactivity $(\mathrm{P} 1$ and N1 ERP components), early conscious attention (N2 ERP component), and late emotion regulation ( $\mathrm{P} 3$ and late positive potential (LPP) ERP components) during reappraisal and suppression instructions. The $\mathrm{P} 1$ component is a positive wave form occurring approximately $100 \mathrm{~ms}$ poststimulus onset which indexes early preconscious visual processing (Hillyard \& Anllo-Vento, 1998; Luck, Woodman, \& Vogel, 2000; Lusk, Carr, Ranson, Bryant, \& Felmingham, 2015). N1 and $\mathrm{N} 2$ are negative wave forms occurring approximately $100 \mathrm{~ms}$ and $200 \mathrm{~ms}$ poststimulus onset that index early preconscious and early conscious attention allocation, respectively (Dong, Zhou, Zhao, \& Lu, 2011; Schupp, Flaisch, Stockburger, \& Junghofer, 2006). P3 is a positive wave form that appears approximately $300 \mathrm{~ms}$ poststimulus, which is thought to index conscious allocation of cognitive resources to emotionally salient stimuli (Moser, Krompinger, Dietz, \& Simons, 2009; Olofsson, Nordin, Sequiera, \& Polich, 2008). The LPP is a positive wave form occurring approximately $600 \mathrm{~ms}$ poststimulus onset, which is considered a robust electrophysiological marker of later, conscious, response-related emotion regulation (Hajcak, MacNamara, \& Olvet, 2010).

Despite growing evidence regarding the relevance of sex hormones for emotional processing (for a review, see Toffoletto, Lanzenberger, Gingell, Sunderstom-Poromaa, \& Comasco, 2014), previous sex differences and emotion regulation studies have typically failed to control for the influence of menstrual cycle phase. The menstrual cycle is divided into follicular and luteal phases; the follicular phase includes all days from the first day of menstruation to the day prior to ovulation, while the luteal phase includes all days from the first day of ovulation to the last day before the next menstruation period (Becker et al., 2005; Martin \& Behbehani, 2006; Sunderstom-Poromaa \& Gingnell, 2014). The follicular and luteal phases can be further subdivided into early, mid, and late time phases (Guapo et al., 2009; Sunderstom-Poromaa \& Gingnell, 2014). Estradiol levels are low during the early to midfollicular phases, peak during the late follicular and early luteal phase, plateau during the midluteal phase, and fall to low levels again prior to menstruation (Schuster, Karlsson, Karlstrom, Poromaa, \& Dahl, 2010; Speroff \& Fritz, 2010). Progesterone levels are extremely low during the follicular phase, peak during the midluteal phase, and then fall precipitously to low levels during the late luteal phase (Becker et al., 2005; Marshall, 2001; Martin \& Behbehani, 2006; Nikas \& Makrigiannakis, 2003; Solis-Ortiz \& Corsi-Cabrera, 2008; Sunderstom-Poromaa \& Gingnell, 2014). Wu, Zhou, and Huang (2014a) did consider the impact of menstrual phase on emotion processing by examining subjective and skin conductance responses during the early follicular, late follicular, and mid-late luteal phases. Wu et al. (2014a) demonstrated 
that while early follicular women reported higher levels of reappraisal, subjective reports of sadness did not differ between the three menstrual phases. Wu et al. (2014a) also showed that reappraisal effects on skin conductance responses were smaller in early follicular women relative to mid-late luteal women.

Sexual dimorphism in the function and structure of the limbic network (e.g., amygdala, hippocampus) and frontal regions are well documented (e.g., Domes et al., 2010; Goldstein, Kennedy, \& Caviness, 1999; Goldstein et al., 2001; Lebron-Milad et al., 2012; Lebron-Milad \& Milad, 2012; McRae et al., 2008), with such areas implicated in emotion processing and emotion regulation. Neuroimaging emotion studies have also documented substantial menstrual cycle modulation of limbic and frontal regions. For example, reduced limbic and frontal region activity during the late follicular phase compared with early follicular phase has been demonstrated (Goldstein et al., 2005; Goldstein, Jerram, Abbs, Whitefield-Gabrieli, \& Makris, 2010), with such findings indicating that circulating sex hormones help explain sex differences in brain activity in these regions. This interpretation is consistent with other fMRI studies such as Protopopescu et al. (2005), who reported greater anterior-medial orbitofrontal activity to unpleasant relative to neutral stimuli during the luteal phase relative to the follicular phase, whereas the inverse pattern was observed in the lateral orbitofrontal cortex. Further, estradiol receptors have been shown to be most concentrated in the limbic area and prefrontal cortices (Montague et al., 2008; Spencer et al., 2008; Walf \& Frye, 2006) and estradiol therapy has been found to selectively improve executive functioning by reducing prefrontal cortex activation (Joffe et al., 2006). Increased amygdala and hippocampus activation has been seen during the midluteal phase compared to the early follicular phase (Andreano \& Cahill, 2010). Van Wingen et al. (2008) found increased activity in the amygdala and the hippocampus following an exogenous dose of progesterone that matched levels observed naturally during the midluteal phase. Menstrual phase modulation of limbic and frontal regions may thus impact on emotional reactivity and later emotion regulation processes (Etkin, 2009; Farb et al., 2012). Taken together, these findings therefore suggest that low sex hormone levels produce lower limbic system and frontal region activation, which subsequently would result in improved emotion regulation capacity.

Only a small number of recent ERP studies have investigated the impact of menstrual phase, and these studies have reported conflicting results. Investigating the processing of neutral and moderately and highly unpleasant visual stimuli across mid-late luteal and mid-late follicular menstrual phases, Wu et al. (2014b) found N2 amplitude to be greater to both moderately and highly unpleasant stimuli compared with neutral stimuli during the mid-late luteal phase, with no difference demonstrated during the mid-late follicular phase.
This finding supports the negativity bias in midluteal women as it indicates that the processing bias is markedly stronger in midluteal relative to early follicular women, which echoes recent neuroimaging findings (e.g., Andreano \& Cahill, 2010). Contrasting LPP findings have been reported, as Zhang, Zhou, Wang, Zhao, and Liu (2015) showed luteal phase modulation of the LPP relative to the early and late follicular phases, whereas Zhang, Zhou, and Ye (2013) demonstrated increased LPP amplitude during the mid-late luteal phase compared to the early and late follicular phases. A recent study by Lusk et al. (2015) found that midluteal women displayed increased automatic visual processing to emotional and neutral stimuli and suggested that this greater early visual processing may have implications for later emotion regulation. Given the limbic system has been shown to be modulated by menstrual phase (Andreano \& Cahill, 2010), there is a need for further research to explore whether menstrual phase impacts emotion regulation processing.

Few ERP studies have extended existing sex differences and emotion literature to investigate sex differences in emotion regulation. $\mathrm{N} 1$ and $\mathrm{N} 2$ amplitudes have been found to be significantly greater in women compared to men (Lithari et al., 2010) irrespective of emotion regulation instruction (Gardener et al., 2013). Similarly, while Li, Yuan, and Lin (2008) revealed greater $\mathrm{N} 2$ and $\mathrm{P} 3$ amplitude in both men and women to highly unpleasant than to neutral stimuli, moderately unpleasant stimuli were shown to produce increased N2 and P3 amplitudes in women but not men. P3 activation has been shown to reflect modulation of emotional responses before later emotion regulation processes (Moser et al., 2009; Olofsson et al., 2008). Modified by emotional instruction, LPP amplitude has been shown to be lower when one's emotional response is decreased and higher when emotional reactivity is increased (Hajcak \& Nieuwenhuis, 2006; Moser et al., 2009). In response to an "increase" emotion instruction, women display greater LPP activation than men, but sex differences to a "decrease" emotion instruction were not observed (Gardener et al., 2013). Collectively, these ERP findings demonstrate increased early emotional reactivity and greater engagement of emotion regulation processes in women compared to men. To our knowledge, no ERP emotion regulation studies have previously investigated sex differences, and the impact of menstrual phase on emotion regulation processing.

The aim of the current study was to investigate the effect of menstrual phase on cortical processing during emotion regulation (reappraisal and suppression). We used high temporal resolution ERPs to investigate sex differences in the cortical processing of emotion regulation while controlling for menstrual phase. Specifically, we employed an emotion regulation task adapted from the methodologies of Moser, Most, and Simons (2010) and Goldin et al. (2008) to compare conscious emotion regulation processing in men, women in their early follicular menstrual phase (characterised by low levels of 
estradiol and progesterone), and women in their midluteal menstrual phase (characterised by high levels of estradiol and progesterone). We predicted that women in the midluteal phase would display greater N1 and P1 amplitude to unpleasant stimuli and greater difficulty in decreasing negative emotional processing (reflected in greater emotional distress and effort ratings, and smaller reduction in P3 and LPP amplitudes) than men and women in the early follicular phase.

\section{Method}

\section{Participants}

Eighty-four healthy, right handed, nonsmoking, Caucasian adults participated in this study. Participants were 28 women in the early follicular phase (Day 2-6; $M=3.54, S D=1.66$; low estradiol/low progesterone) of their menstrual cycle (age range: $18-44$ years; $M=23.54, S D=6.60$ ), 29 women in the midluteal phase (Day 18-24; $M=20.90, S D=1.86$; high estradiol/high progesterone; age range: $18-40$ years; $M=23.45, S D=7.51$ ), and 27 men (age range: $18-40$ years; $M=24.41, S D=7.16$ ). Three women currently prescribed a combination contraceptive pill and tested on Day 4 of their sugar pill while menstruating were included in the early follicular sample. Analyses of all data sets were conducted with and without the three women on contraceptives. Removal of these participants did not affect the findings and therefore the full early follicular sample (including those on the contraceptive pill) is reported. To ensure accuracy of menstrual phase allocation, women contacted the investigator on Day 1 of their menses and were tested in the early follicular phase when menstruating or were scheduled for testing during the midluteal phase, calculated from their first day of menstruation. Women were deemed ineligible for this study if they were pregnant or possibly pregnant, had been pregnant or given birth during the previous 12 months, reported a typical monthly menstrual cycle below 27 days or above 29 days, had currently or previously experienced abnormal or irregular menstrual cycles, menopause, or reported any type of abnormal hormonal condition. Participants who reported medication use, substance abuse or dependence, a history of neurological disorders, brain injury or loss of consciousness greater than five minutes, mood disturbance, or anxiety in response to the visual stimuli in the experimental task were excluded from this study. It should be noted that the same participants were recruited for Lusk et al. (2015) and the current study; however, different experimental tasks (passive viewing vs. emotion regulation) containing different stimuli, and completed in counterbalanced order were used. Participants gave written informed consent and this study had ethical approval from the Tasmanian Social Sciences Human Research Ethics Committee.

\section{Stimuli and materials}

Emotion Regulation Scale Participants completed the Emotion Regulation Scale (ERS; Gross \& John, 2003) prior to experimental task completion to assess trait emotion regulation style. The ERS is a 10-item self-report measure of trait emotion regulation, which assesses the extent of reappraisal and suppression emotion regulation strategies used. The ERS is composed of a Reappraisal subscale (6 items) and a Suppression subscale (4 items). The mean of ERS scores for each subscale was calculated, which provided an estimate of the extent to which participants engaged in each emotion regulation strategy. Test-retest reliability for both scales is .69 (Gross \& John, 2003), and Chronbach's alphas are $a=.81$ and $a=.75$ for the Reappraisal and Suppression subscales, respectively (Amstadter \& Vemon, 2008).

Depression, Anxiety, Stress Scale Completed by participants prior to testing, the 42-item self-report Depression, Anxiety, Stress Scale (DASS; Lovibond \& Lovibond, 1995) was used to provide an estimate of participant's level of depressed, anxious, and stressed mood on the day of testing. The DASS is a highly reliable measure of depression $(a=.95)$, anxiety $(a=.90)$, and stress ( $a=.93$; Lovibond \& Lovibond, 1995).

Emotion regulation task A computer-based emotion regulation picture-viewing task adapted from Moser et al. (2010) and Goldin et al. (2008) was used. The task comprised two different blocks of emotion regulation instructions ("reappraisal" and "maintain" or "suppression" and "maintain"), and each block presented the same 60 highly arousing unpleasant International Affective Picture System (IAPS; Lang, Bradley, \& Cuthbert, 2008) images ${ }^{1}$ in randomised order, which was counterbalanced according to Latin square procedures. IAPS normative data guided image selection; similar to Moser et al. (2010); mean valence: 2.55 , mean arousal: 6.48 , the mean valence and arousal ratings were 2.81 and 6.04 , respectively. The experimental images included scenes involving animal and human mutilation, injury, assaults, and death. Neutral stimuli were not presented, as it is not possible to regulate an emotional response to a neutral stimulus (Moser et al., 2010).

Each block contained 30 maintain and 30 regulation (reappraisal or suppression) trials. Reappraisal and suppression instructions were adapted from those used by

\footnotetext{
${ }^{1}$ IAPS images used in this experiment - Animal Threat: 1033, 1050, 1120, $1202,1205,1300,1301,1303,1304,1310,1321,1525,1820,1931,1932$; Animal Mutilation: 6415, 9140, 9145, 9150, 9171, 9180, 9181, 9182, 9183, 9185, 9186, 9560, 9561, 9570, 9571; Human Threat: 3500, 3530, 6021, 6212, 6213, 6220, 6260, 6312, 6350, 6520, 6550, 6821, 6825, 6830, 9452; Human Mutilation: 3000, 3001, 3010, 3015, 3051, 3064, 3069, 3195, 3213, 3215, 3261, 3280, 9042, 9420, 9433.
} 
Goldin et al. (2008), while the maintain instruction was that used by Moser et al. (2010). The reappraisal prompt was "think objectively," and participants were instructed to "think objectively to decrease any emotional response you might have to the image by viewing the image with a detached third-person perspective, thinking of the image content as being not personally relevant, or thinking of the image content as being fake." The reappraisal instruction aimed to alter the antecedent interpretation of the stimuli to decrease participant's emotional response. The suppression prompt was "keep face still," and participants were instructed to "keep your face still, but do not change the way you are feeling inside. Continue to experience your emotions as you normally would. But please keep your face still so that someone watching you could not tell how you are feeling inside." The suppression instruction aimed to reduce the emotional reaction to the stimuli experienced by the participants. The maintain instruction prompt was "watch," and participants were instructed to "watch the image normally as you would if you were watching TV on your couch at home. Do not change the way you would normally respond to the image, and experience your emotions normally." The instruction prompts also acted as a fixation point in the center of the screen to orient the participant's attention and instruct them in how to respond to the next upcoming image. Reappraisal and suppression instructions were presented in separate blocks to avoid any contamination of emotion regulation strategies within each block (e.g., switching from reappraisal to suppression on successive trials; Goldin et al., 2008; Monsell, 2003; Moser et al., 2010). The instruction was presented for 3,000 ms, stimuli were then immediately presented for $5,000 \mathrm{~ms}$, and an interstimulus interval of $3,000 \mathrm{~ms}$ then followed.

Post-task manipulation check Following the experimental task, a questionnaire was used to obtain qualitative responses from participants as a task manipulation check to assess capacity to follow emotion regulation instructions. Participants reported the strategies they had used when following each task instruction (reappraisal, suppression, or maintain). Perceived emotional distress experienced while following each instruction type was rated on a 7-point Likert scale $(1=$ very weak, $7=$ very strong). Perceived degree of effort required to regulate one's emotional reaction for each instruction strategy was also assessed on a 7-point Likert scale $(1=$ very little, $7=$ very much).

Salivary estradiol and progesterone Salivary measures of baseline estradiol and progesterone were taken to enable confirmation of menstrual cycle states in women (Gandara, Leresche \& Mancl, 2007). Participants refrained from consuming food, caffeine, and nicotine for three hours prior to the study and avoided alcohol or excessive exercise for 24 hours prior to the study in order to control for potential confounds on hormonal or ERP responses (e.g., Brot, Koob, \& Britton, 1995; Fabiani, Gratton, \& Coles, 2000; Polich, 2007). Saliva samples were self-collected from participants in tubes using the standard passive drool method (Shirtcliff, Granger, Schwartz, \& Curran, 2001), immediately frozen, and stored at $-20{ }^{\circ} \mathrm{C}$ until assay. On analysis day, specimens were thawed and centrifuged at $1500 \times \mathrm{g}$ for 15 minutes at room temperature. Estradiol and progesterone concentrations were determined by enzyme immunoassay with commercially available kits (Q-111 HS Salivary 17- $\beta$ Estradiol EIA and Q112 Salivary Progesterone EIA kits; rabbit antiestradiol/ progesterone antibodies; Salimetrics, State College, Pennsylvania, USA) in the Pathology Laboratory in the Division of Pharmacy at the University of Tasmania (UTAS), Australia. Estradiol data were not analysed because extremely low values in all participants suggested artefactual data.

\section{Procedure}

Participants attended the Cognitive Neuroscience Laboratory at UTAS for one 2-hour testing session. Participants completed the ERS (Gross \& John, 2003) and DASS (Lovibond \& Lovibond, 1995), and saliva samples were collected. Participants were prepared for EEG recording as described below and were then seated 0.5 meters from a 17 -inch computer screen in a sound-attenuated room. Participants were instructed to maintain eye contact with the computer screen and to limit eye and body movements throughout the task.

Similar to Moser et al. (2010), prior to the experimental task presentation, participants completed two 15 -trial training blocks to familiarise them to the task and ensure that they understood and could adhere to the reappraisal, suppression, and maintain instructions. During the first training block, participants were required to verbally report the strategies they were using to appraise the stimuli in accordance with the instructional prompts. This training block provided the investigator with the opportunity to mold the strategies used by the participants and establish whether they understood the task. During the second training block, participants were required to silently produce the appropriate strategies that they would use to appraise the stimuli in line with the instructional prompts as they would do during the experimental task. Participants viewed the stimuli presented on the screen, in line with each instruction, and were told that they would be asked questions regarding the stimuli (i.e., perceived valence/arousal) after the emotion regulation task to ensure that they attended to the stimuli. As an additional instruction manipulation check, the investigators reviewed the participants' responses on the posttask questionnaire to determine whether or not participants understood the instructions and reported using strategies typical of previous research findings (e.g., Ochsner $\&$ Gross, 2005) before their data were included in analysis. 
Following the task, each stimulus was then independently rated for level of valence and arousal by participants on a 9point Likert scale adapted from the IAPS normative data rating scale (Self-Assessment Manikin; Bradley \& Lang, 1994): valence $(1=$ highly unpleasant, $5=$ neutral, $9=$ highly pleasant); arousal $(1=$ not at all exciting/arousing, $5=$ mod erately arousing, $9=$ highly exciting/arousing).

\section{Electrophysiological apparatus and recording}

EEG activity was recorded from 32 sites according to the international 10-20 system (Jasper, 1958) using a Quik-Cap with silver and silver chloride $(\mathrm{Ag} / \mathrm{AgCl})$ electrodes and SynAmps 2 amplifiers. All electrode sites were referenced to linked mastoids, and an AFz ground was used. Horizontal electrooculographic (EOG) activity was recorded from electrodes placed at the outer canthus of both eyes, while vertical EOG activity was recorded from electrodes above and below the left eye. Electrode impedance was kept below $10 \mathrm{~K} \Omega$, and EEG data were sampled at $1000 \mathrm{~Hz}$ and amplified with a high-pass filter of $0.15 \mathrm{~Hz}$ and low-pass filter of $100 \mathrm{~Hz}$. EEG data were merged with behavioral files, and vertical and horizontal ocular artifact reduction was conducted using an algorithm developed by Compumedics Neuroscan (2006), based on combined regression analysis and artifact averaging (Semlitsch, Anderer, Schuster, \& Presslich, 1986). Continuous data files were then low-pass filtered at $30 \mathrm{~Hz}$ at $48 \mathrm{~dB}$ per octave, epoched off-line for a 1,000 ms epoch commencing $100 \mathrm{~ms}$ before stimulus onset, and baseline corrected. High and low cut-offs for artifact rejections were setat $100 \mu \mathrm{V}$ and $-100 \mu \mathrm{V}$, respectively. EEG activity corresponding to each instruction block was averaged and filtered with a high-band pass of $0.15 \mathrm{~Hz}$ and a low pass of $30 \mathrm{~Hz}$.

In accordance with previous research and grand mean visual inspection, $\mathrm{N} 1$ and $\mathrm{N} 2$ were defined as the peak negativities within $50-150 \mathrm{~ms}$ and $200-350 \mathrm{~ms}$ poststimulus onset, respectively, over frontocentral electrodes (FC3, FCZ, FC4; Li et al., 2008). The $\mathrm{P} 1$ component, which indexes early sensory processing within the extrastriate visual cortex, was determined as the peak positivity within $60-120$ ms poststimulus onset over occipital electrodes (O1, OZ, O2; Olofsson et al., 2008). $\mathrm{P} 3$ was measured as the peak positivity within the 250 450-ms time window over parietal sites (P3, PZ, P4; O'Reilly, Cunningham, Lawlor, Walsh, \& Rowan, 2004). The LPP was determined as the mean positivity within $450-700 \mathrm{~ms}$ and 1,000-3,000 ms poststimulus onset time windows over parietal sites (P3, PZ, P4; Krug, Plihal, Fehm, \& Born, 2000; Strauss et al., 2013; Wu et al., 2013).

\section{Design and data analysis}

Separate univariate ANOVAs with group as the between-subjects factor were conducted to assess any group differences in age, selfreported depressed mood, anxiety, and stress (as measured by the
DASS), self-reported reappraisal and suppression emotion regulation strategies (as measured by the ERS), stimuli mean valence and arousal ratings (as measured by the picture-viewing task), and self-reported perceived emotional distress and effort required when following reappraisal, suppression, and maintain instructions (as measured by the post-task questionnaire).

Peak amplitudes of N1, N2, P1, and P3 and the mean amplitude of the LPP were analysed using 3 (group: early follicular, midluteal, men) $\times 2$ (instruction: reappraise, maintain or suppression, maintain) $\times 3$ (site: FC3, FCZ, FC4 or P3, PZ, P4 or $\mathrm{O} 1, \mathrm{OZ}, \mathrm{O} 2$ ) mixed-factorial ANOVAs. The inclusion of emotion regulation and baseline (maintain) instructions within the same block created potential for baseline associated cortical activity to be impacted by the regulation instruction. To rule out potential baseline differences between the maintain instructions in the reappraisal and suppression blocks, separate 3 (group: early follicular, midluteal, men] $\times 2$ (instruction: maintain [reappraise], maintain [suppression]) $\times 3$ (site: FC3, FCZ, FC4 or P3, PZ, P4 or O1, OZ, O2) mixed-factorial ANOVAs were conducted for each ERP component. ${ }^{2}$

Artefactual (e.g., evidence of visual or physiological artifact) electrode data values were replaced with the mean score of the surrounding electrodes. Three channels (FT7, FT8, FP2) were classified as artefactual for all participants, but these were not channels that were analysed. Outlier checking was conducted and data points greater than three standard deviations above the mean were identified as outliers. To maintain the range and relative ordering of scores, outliers were replaced with a value .1 below this three standard deviation cutoff (Osborne \& Overbay, 2004; Tabachnick \& Fidell, 2013). Greenhouse-Geisser corrections were made where appropriate, significance levels were maintained at alpha $<.05$, and Sidak-corrected pairwise comparisons were used to test for significant differences between individual means. Effect sizes were measured using partial eta squared $\left(\eta_{\mathrm{p}}{ }^{2}\right)$ and Cohen's $d$ (Cohen, 1988) is reported for results involving group differences to provide a clinically relevant effect size. Data were analyzed using the Statistical Package for the Social Sciences (SPSS; Version 21). Obtained results involving electrode site were not reported unless involved in an interaction of hypothesised significance with group or instruction.

\section{Results}

\section{Salivary progesterone}

A univariate ANOVA demonstrated that women in the midluteal phase had significantly higher progesterone levels

\footnotetext{
${ }^{2}$ The current study did not examine latency, as we were interested in the level of cortical responsiveness to the experimental stimuli rather than the speed of processing.
} 
$(M=195.04, S D=93.39$, median $=177.50)$ than women in the early follicular phase $(M=89.65, S D=91.92$, median $=$ $65.35), F(2,81)=20.70, M S E=6,553.74, p<.001$, $\eta_{\mathrm{p}}{ }^{2}=.359, d=1.33, H(1)=9.59, p=.002 .^{3}$

\section{Clinical and demographic data}

No significant differences were found between men, early follicular women, and midluteal women in age, depressed mood, anxiety, stress, or emotion regulation strategies ( $p$ $\mathrm{s}>.05$; see Table 1).

\section{Picture rating task}

Early follicular and midluteal women both rated the unpleasant images as significantly more unpleasant (early follicular: $d=1.59$; midluteal: $d=1.94$ ) and significantly more arousing (early follicular: $d=2.52$; midluteal: $d=4.25$ ) relative to men, with midluteal women rating the images as significantly more arousing than the early follicular women $(p s<.001, d=1.72$; see Table 1).

\section{Post-task manipulation check}

A review of the qualitative data from the post-task manipulation check questionnaire established that all participants were able to follow each emotion regulation instruction, with participants reporting similar reappraisal, suppression or maintain strategies. Specifically, all 84 participants reported the use of cognitive reappraisal to reduce their emotional response following the reappraise instruction (e.g., "I told myself that the images were fake"). All 84 participants also reported reducing their emotional response following the suppression instruction (e.g., "I internalised my emotions to reduce the emotional reaction I had to the images by not showing external indicators of how I was feeling"). All 84 participants were also able to successfully maintain their emotional responses to the maintain instruction (e.g., "I viewed the image as I normally would and focused on the feelings naturally associated with the image").

Significant group effects revealed that both early follicular ( $p=.002, d=.89)$ and midluteal $(p=.02, d=.64)$ women reported greater emotional distress than men when suppressing emotional response. However, during suppression, midluteal women also reported using more effort at trend-level significance than early follicular women $(p=.06, d=.51)$ and significantly more effort than men ( $p=.02, d=.67$; see Table 2$)$.

\footnotetext{
${ }_{3}^{3}$ Due to concerns of potential nonnormality of salivary hormonal data, a nonparametric equivalent test (Kruskal-Wallis) was conducted to ensure any potential nonnormality did not bias the results; this showed no contradictory results.
}

\section{Baseline maintain (reappraisal) versus maintain (suppression) instruction}

A significant main effect of instruction demonstrated that N2 amplitude was significantly greater to the maintain instruction during the suppression $(M=-6.43, S D=.60)$ compared to the reappraisal $(M=-5.55, S D=.62)$ block, $F(1,81)=4.20$, $M S E=23.43, p=.04, \eta_{\mathrm{p}}{ }^{2}=.049$. No other significant baseline differences were found for any ERP component.

\section{Reappraisal versus maintain instruction}

P1: A significant main effect of Instruction showed that P1 amplitude was significantly greater to reappraisal compared to the maintain instruction, $F(1,81)=99.54, M S E=44.08$, $p<.001, \eta_{\mathrm{p}}{ }^{2}=.551$. A significant effect of group, $F(2$, $81)=3.21, M S E=37.85, p=.046, \eta_{\mathrm{p}}{ }^{2}=.073$, was superseded by a Group $\times$ Site interaction, $F(3.74,81)=3.23, M S E=$ $9.55, p=.016, \eta_{\mathrm{p}}{ }^{2}=.074$. As shown in Fig. 1, Sidak post hoc tests demonstrated that midluteal women had significantly greater $\mathrm{P} 1$ activity compared to men at $\mathrm{O} 1$ site $(p=.01$, $d=.83$ ), with activity also trending higher at $\mathrm{O} 2$ site $(p=.06, d=.63)$. No other significant main effects or interactions were found for P1 amplitude.

N1: As displayed in Fig. 2, a significant main effect of group, $F(2,81)=3.73, M S E=57.21, p=.03, \eta_{\mathrm{p}}{ }^{2}=.084$, revealed that midluteal women had significantly greater $\mathrm{N} 1 \mathrm{am}-$ plitude than men $(p=.02, d=.74)$. No other significant main effects or interactions for N1 amplitude were found.

N2/P3: No significant main effects or interactions were found for $\mathrm{N} 2$ or $\mathrm{P} 3$ amplitudes.

LPP: During the 450-700-ms time window, no significant main effects or interactions were found. However, a significant main effect of instruction was found during the 1,000 3,000-ms time window, $F(1,81)=5.14, M S E=32.62, p=.03$, $\eta_{\mathrm{p}}{ }^{2}=.060$, which showed LPP amplitude to be significantly greater to reappraisal compared with maintain instruction. No other significant main effects or interactions for LPP amplitude were found.

\section{Suppression versus maintain instruction}

P1: A main effect of instruction, $F(1,81)=113.29, M S E=$ $42.88, p<.001, \eta_{\mathrm{p}}{ }^{2}=.583$, demonstrated significantly greater P1 amplitude to suppression compared with maintain instruction. No other significant main effects or interactions for P1 amplitude were found.

N1: Sidak post hoc tests investigating a trend towards a significant main effect of group, $F(2,81)=2.83, M S E=$ $74.35, p=.06, \eta_{\mathrm{p}}{ }^{2}=.065$, showed midluteal women had greater $\mathrm{N} 1$ amplitude than men $(p=.06, d=.64$; see Fig. 3$)$. No other significant main effects or interactions for N1 were found. 
Table 1 Mean age, depression, anxiety, and stress scores, valence and arousal ratings, and reappraisal and suppression emotion regulation strategies for early follicular women, midluteal women, and men

\begin{tabular}{llllll}
\hline Variable & Early follicular women & Midluteal women & Men & $F$ & $\eta_{\mathrm{p}}{ }^{2}$ \\
\hline Age & $23.54(6.60)$ & $23.45(7.51)$ & $24.41(7.16)$ & .414 & .66 \\
Depressed Mood & $5.18(8.71)$ & $4.76(6.44)$ & $3.30(3.45)$ & .616 & .016 \\
Anxiety & $3.64(4.57)$ & $4.84(4.84)$ & $2.85(3.21)$ & 1.198 & .31 \\
Stress & $8.11(6.80)$ & $8.14(6.59)$ & $6.04(5.16)$ & 1.023 & .015 \\
Valence & $1.97(.43)$ & $1.76(.84)$ & $2.97(.57)$ & 28.361 & .029 \\
Arousal & $5.63(1.28)$ & $7.85(1.27)$ & $2.39(1.34)$ & 122.732 & $<.001$ \\
Reappraisal & $4.83(1.02)$ & $4.59(1.08)$ & $5.24(1.34)$ & 2.29 & .025 \\
Suppression & $3.19(.97)$ & $3.24(1.16)$ & $3.64(1.38)$ & 1.20 & .712 \\
\hline
\end{tabular}

Note: Standard deviations in parentheses. No significant differences were found between participants in demographics. Early follicular and midluteal women both rated the unpleasant images as significantly more unpleasant and significantly more arousing relative to men, with midluteal women rating the images as significantly more arousing than the early follicular women. No significant differences were found between men, early follicular women, and midluteal women in trait emotion regulation strategy

N2: A main effect of Instruction, $F(1,81)=17.54$, $M S E=12.68, p<.001, \eta_{\mathrm{p}}{ }^{2}=.178$, showed N2 amplitude to be significantly greater to suppression compared to maintain instruction. As shown in Fig. 4, there was a significant Group $\times$ Instruction interaction, $F(2,81)=$ 3.35, MSE $=178.70, p=.04, \eta_{\mathrm{p}}{ }^{2}=.076$ for $\mathrm{N} 2$ amplitude. Sidak post hoc analyses revealed that midluteal women had significantly greater $\mathrm{N} 2$ amplitude to the suppression instruction than men $(p=.04, d=.69)$. No other significant main effects or interactions for N2 amplitude were found.

P3: A significant main effect of instruction, $F(1,81)=$ 4.39, MSE $=15.31, p=.04, \eta_{\mathrm{p}}{ }^{2}=.051$, showed P3 amplitude to be significantly lower to suppression than maintain instruction. No other significant main effects or interactions for P3 amplitude were found.

LPP: No significant main effects or interactions were found for LPP amplitude during either the 450-700-ms or 1,000-3,000-ms time windows.

\section{Correlational data}

To follow up the significant group effects specifically, planned correlations between progesterone and the relevant ERP components collapsed across their respective sites were performed using Pearson's product-moment coefficients (Pearson's $r$ ). As shown in Table 3, following Bonferroni correction, a trend-level significance negative correlation between progesterone and $\mathrm{N} 2$ amplitude during suppression revealed a relationship between increased progesterone levels and increased N2 amplitude following suppression instruction (see Table 3 and Fig. 5). No other significant or trend-level correlations were found between progesterone and ERP component amplitudes during either reappraisal or suppression. Pearson's product-moment correlations conducted between progesterone and distress and effort ratings for the reappraisal and suppression instructions demonstrated no significant or trendlevel relationships between progesterone and distress and effort ratings during reappraisal or suppression (see Table 3).

Table 2 Mean scores for emotional distress and effort, as measured by the posttask manipulation check, to reappraisal, suppression, and maintain instructions for early follicular women, midluteal women, and men

\begin{tabular}{|c|c|c|c|c|c|c|}
\hline Variable & Early follicular women & Midluteal women & Men & $F$ & $p$ & $\eta p^{2}$ \\
\hline Distress (Maintain) & $5.43(1.0)$ & $4.55(1.24)$ & $4.48(1.01)$ & 6.51 & .002 & .138 \\
\hline Distress (Reappraisal) & $3.14(.97)$ & $3.52(1.55)$ & $2.89(1.34)$ & 1.63 & .20 & .039 \\
\hline Distress (Suppression) & $5.07(1.15)$ & $4.72(1.56)$ & $3.85(1.43)$ & 5.58 & .005 & .121 \\
\hline Effort (Maintain) & $4.14(1.38)$ & $4.03(1.55)$ & $4.37(1.50)$ & .37 & .69 & .009 \\
\hline Effort (Reappraisal) & $5.18(1.54)$ & $5.17(1.61)$ & $4.85(1.38)$ & .42 & .66 & .010 \\
\hline Effort (Suppression) & $4.68(1.81)$ & $5.45(1.33)$ & $4.44(1.42)$ & 3.33 & .04 & .076 \\
\hline
\end{tabular}

Note: Standard deviations in parentheses. Early follicular women reported significantly increased emotional intensity compared with both midluteal women and men when maintaining their emotional response. Early follicular and midluteal women reported significantly greater emotional intensity when suppressing their emotional response than men. Midluteal women demonstrated a trend toward utilizing greater effort than early follicular women but reported significantly greater effort required relative to men when suppressing their emotional response 

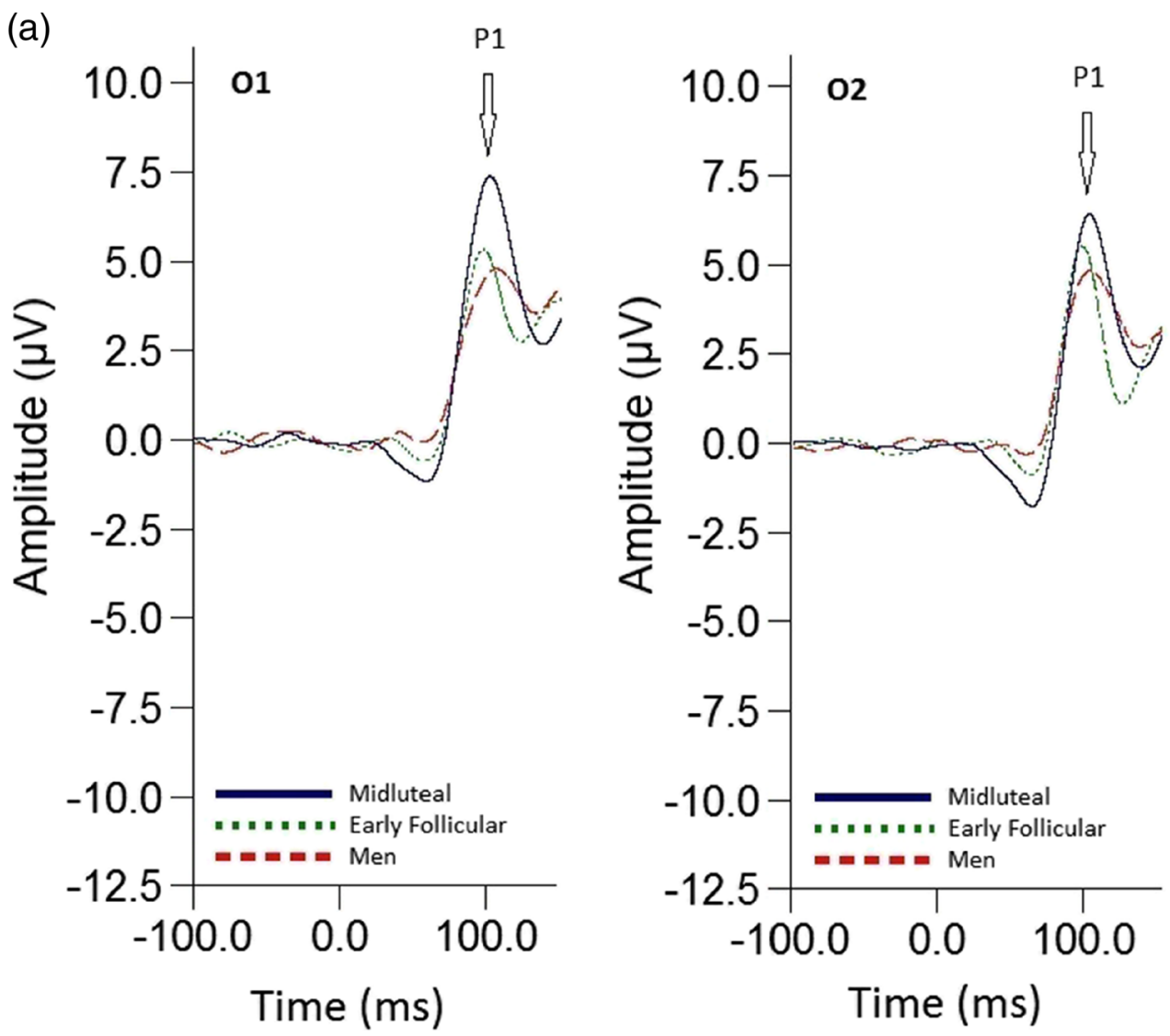

(b)

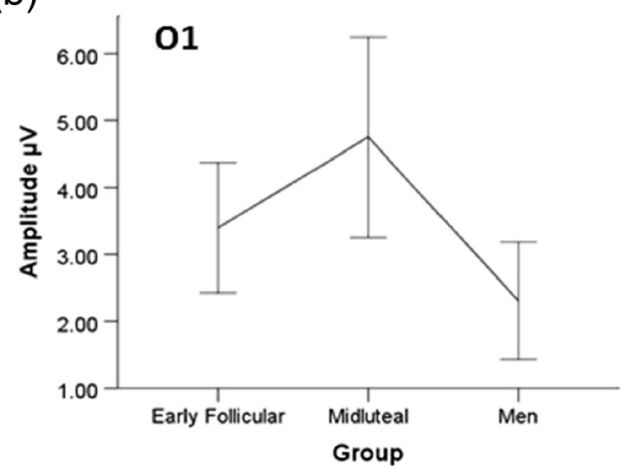

Fig. 1 As represented by a) the ERP waveform and b) $95 \%$ confidence intervals: the Group $\times$ Site interaction for P1 amplitude at O1 (left) and $\mathrm{O} 2$ (right) site collapsed across reappraise/maintain instruction set.

No significant correlations between progesterone level and DASS scores, nor between ERP component amplitudes and DASS scores, during either reappraisal or suppression were revealed. Following Bonferroni correction, during suppression a significant positive correlation between arousal and P1 amplitude and significant negative correlations between arousal and N1 and N2 amplitudes were found. These significant correlations indicated that arousal levels increased as P1, $\mathrm{N} 1$, and $\mathrm{N} 2$ amplitudes increased and support the observed ERP effects during suppression. No other correlations between ERP component amplitudes and valence or arousal

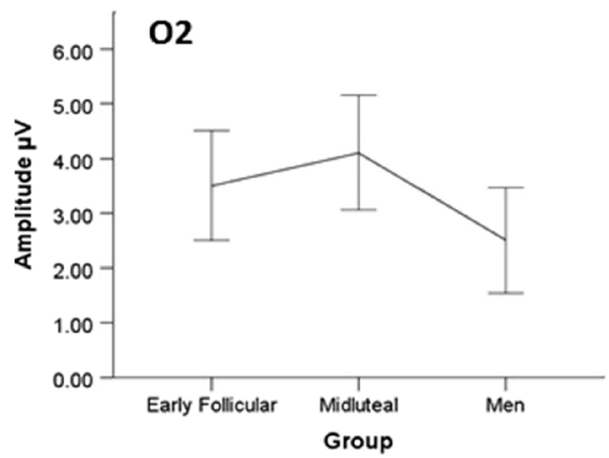

Midluteal women were found to have significantly greater P1 activity compared to men at $\mathrm{O} 1$ site, with activity also trending higher at $\mathrm{O} 2$ site irrespective of emotion regulation instruction. (Color figure online)

ratings were found following either the reappraisal or suppression instruction.

Pearson's product-moment correlations were also performed between the relevant ERP component amplitudes where group effects were found and distress and effort ratings. As shown in Table 4, following Bonferroni correction, there was a significant negative correlation between $\mathrm{N} 1$ amplitude and distress and a trend-level relationship between N1 amplitude and effort ratings, indicating that N1 amplitude increased as distress and effort levels increased. A trend-level negative correlation following Bonferroni adjustment between N1 
(a)

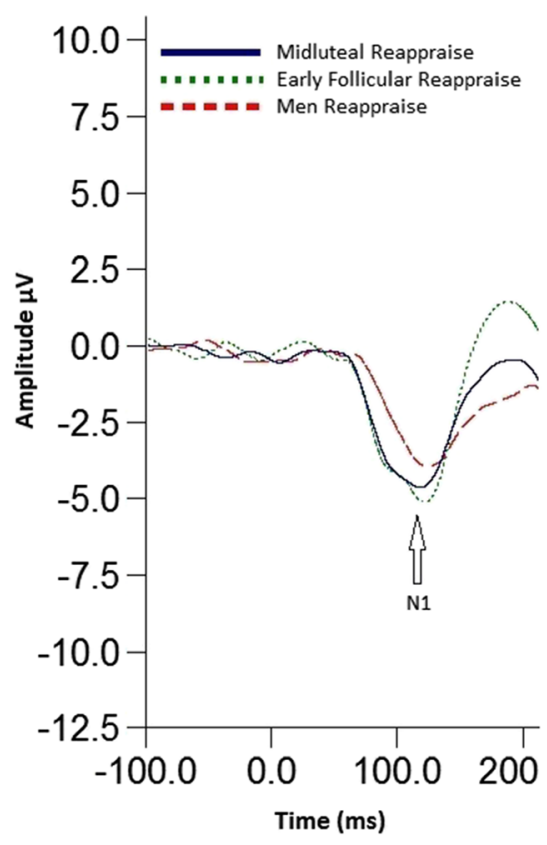

(b)

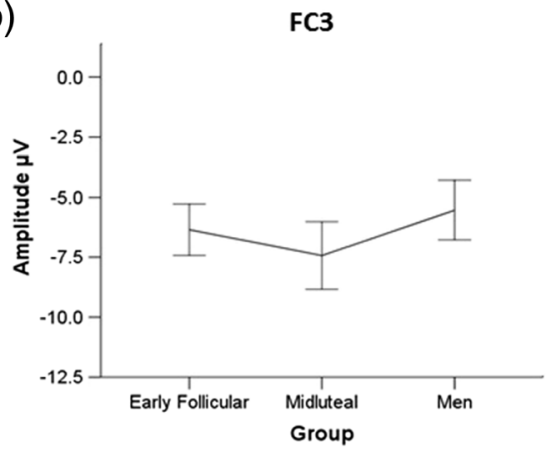

Fig. 2 As represented by a) the ERP waveform and b) $95 \%$ confidence intervals: the group main effect for $\mathrm{N} 1$ amplitude in response to "reappraise" instruction at FC3, FCZ, and FC4 sites. Midluteal women

amplitude and effort during suppression indicated that as effort levels increased N1 amplitude during suppression also increased. No other trend-level or significant correlations between ERP component amplitudes and distress or effort ratings were revealed.

\section{Discussion}

This study examined the impact of menstrual cycle phase on early emotional reactivity and later emotion regulation processing using ERPs, by comparing women in the midluteal phase with women in the early follicular phase and men while completing an emotion regulation task. As expected, midluteal women relative to men displayed an early attentional bias reflected in greater $\mathrm{N} 1$ and $\mathrm{P} 1$ amplitude to unpleasant stimuli. A novel finding of elevated N2 amplitude to
FCZ

FC4

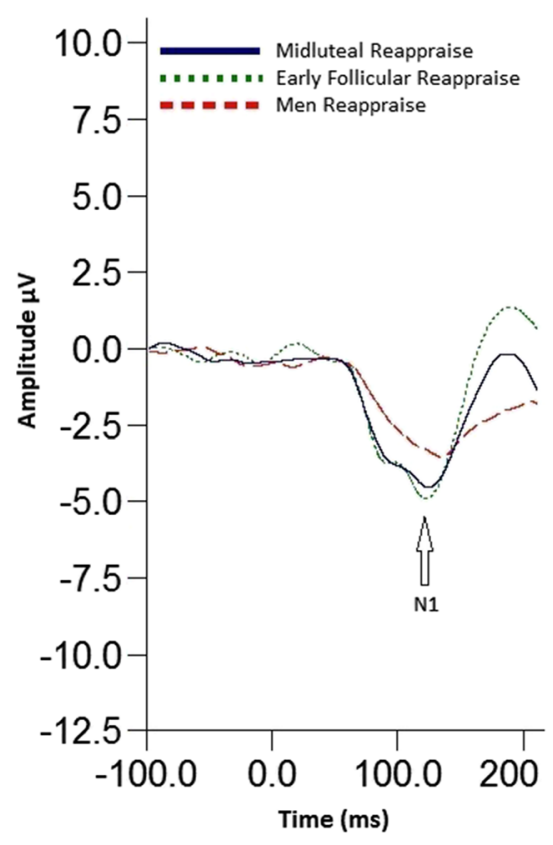

FCZ

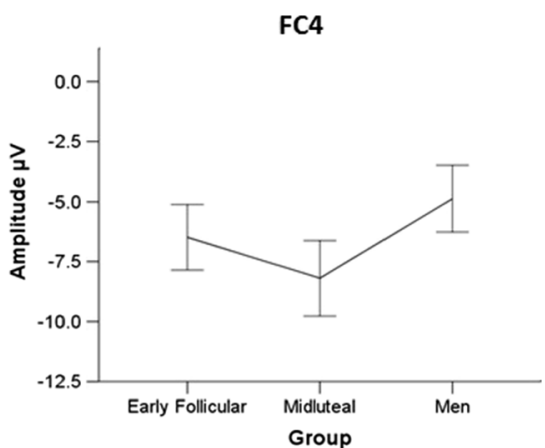

were shown to have significantly greater N1 amplitude than men across all sites during reappraisal. (Color figure online)

unpleasant stimuli during suppression instruction indicated that midluteal women may exhibit greater difficulty in suppressing negative emotional stimuli relative to men. The level of emotional distress experienced during suppression revealed a group effect in that both early follicular and midluteal women reported greater distress compared to men. However, complementing the $\mathrm{N} 2$ finding, the level of effort required when suppressing emotional response to the stimuli demonstrated a menstrual phase effect, with midluteal women utilising significantly greater effort than men and greater effort than early follicular women at trend-level significance.

\section{Early preconscious emotional reactivity: P1 and N1}

Relative to men, midluteal women were shown to have increased early cortical activity, demonstrating significantly greater reactivity than men. When instructed to reappraise 
(a)

FC3

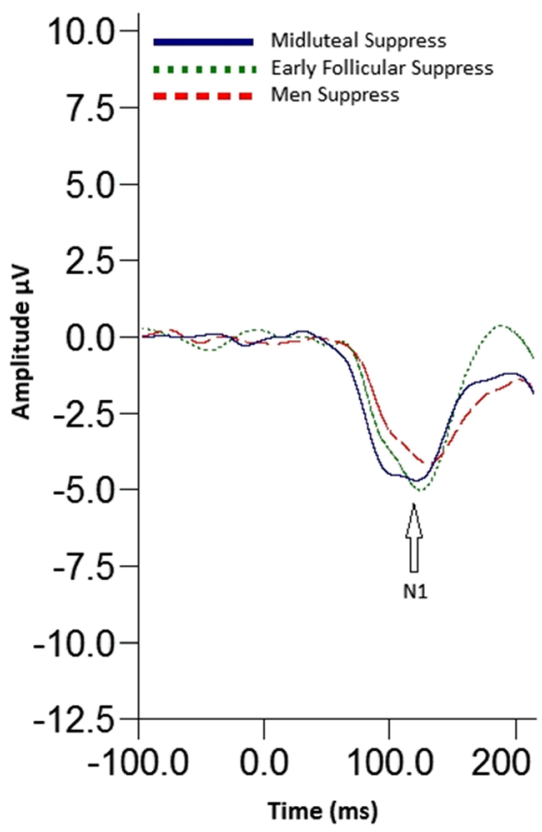

(b)

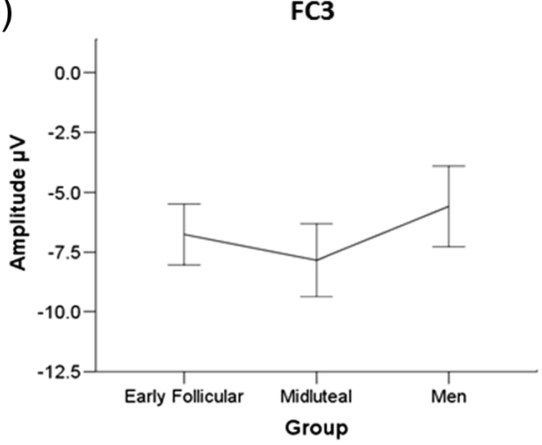

FCZ

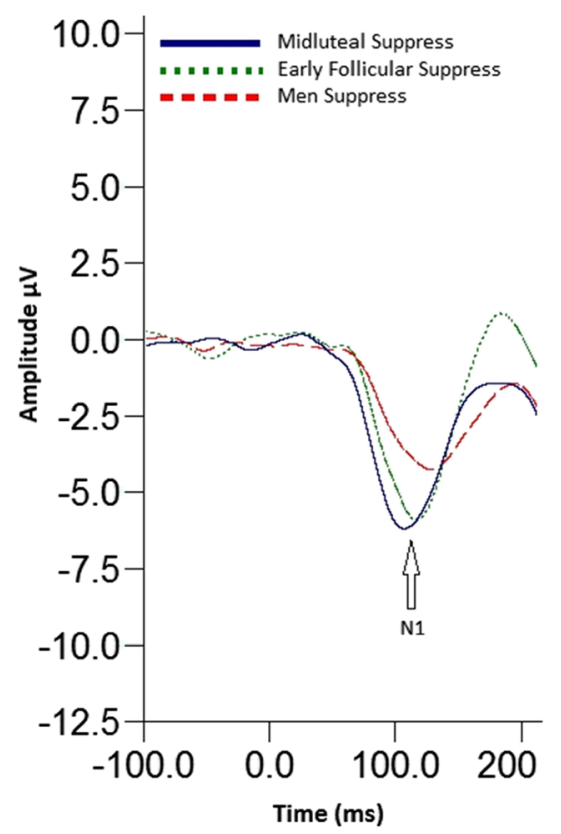

FCZ

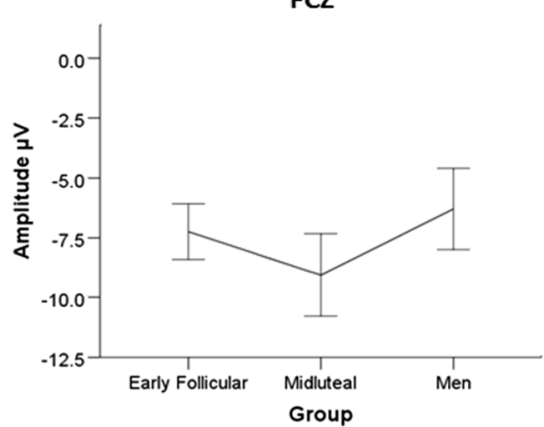

FC4

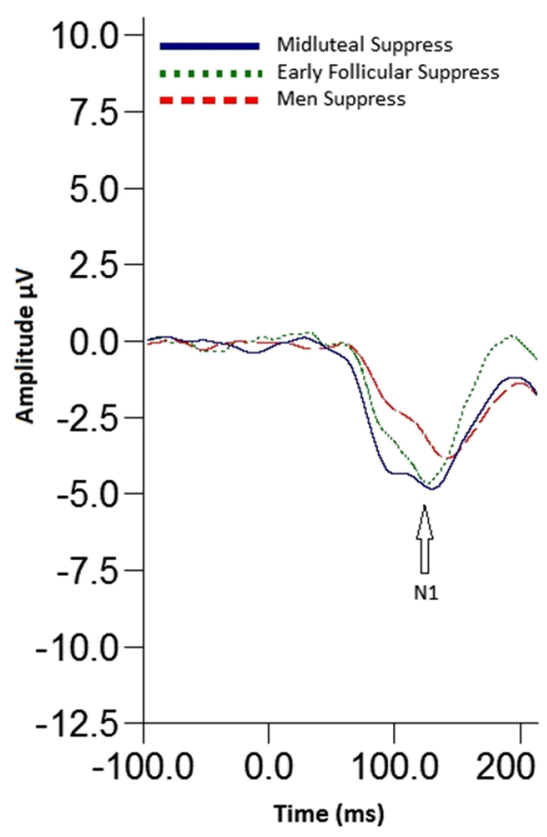

FC4

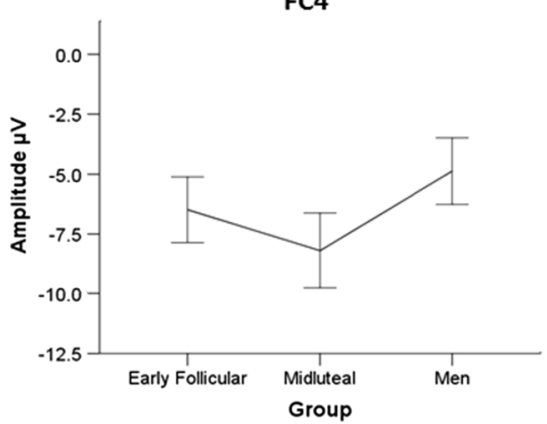

Fig. 3 As represented by a) the ERP waveform and b) $95 \%$ confidence intervals: the group main effect for $\mathrm{N} 1$ amplitude in response to "suppress" instruction at FC3, FCZ, and FC4 sites. Midluteal women

their emotional response to unpleasant stimuli, midluteal women had significantly greater $\mathrm{P} 1$ and $\mathrm{N} 1$ amplitudes during reappraisal compared to men. Of particular importance was that this early preconscious processing bias appeared to be modulated by menstrual phase as midluteal women showed significantly higher P1 activity over occipital sites compared to men (see Fig. 1).

The observed P1/N1 findings in the current study support previous research that demonstrated midluteal women to have enhanced generalised early visual processing (Lusk et al., 2015), from a study using the same participants but a different visual processing (rather than emotion regulation) task. As P1 activation at occipital region indexes early automatic visual attention (Hillyard \& Anllo-Vento, 1998; Luck et al., 2000), the finding of increased P1 for midluteal women relative to men provides electrophysiological evidence that suggests that midluteal women may display greater early preconscious processing of visual emotional stimuli. The present P1/N1 were shown to have significantly greater N1 amplitude than men across all sites during suppression. (Color figure online)

findings are also consistent with recent evidence that the midluteal phase is associated with enhanced visual processing (Wassell, Rogers, Felmingham, Bryant, \& Pearson, 2015; Wassell, Rogers, Felmingham, Pearson, \& Bryant, 2015) and with previous findings of high progesterone levels (as observed in midluteal women) being related to increased capacity for sustained visual attention (Solis-Ortiz \& CorsiCabrera, 2008), greater visual perception ability (Wijayanto, Tochihara, Wijaya, \& Hermawati, 2009), and enhanced visual memory (Phillips \& Sherwin, 1992). Previous research has demonstrated a connection between visual processing regions (including the occipital region) and the amygdala, with amygdala reafferents understood to modulate the early processing of emotional stimuli in the visual cortex (de Kloet, Joëls, \& Holsboer, 2005). As the amygdala is recognised for its relevance to emotion processing and has been shown to have greater activation to negative emotional images in midluteal women (Andreano \& Cahill, 2010), there is a need for 
(a)

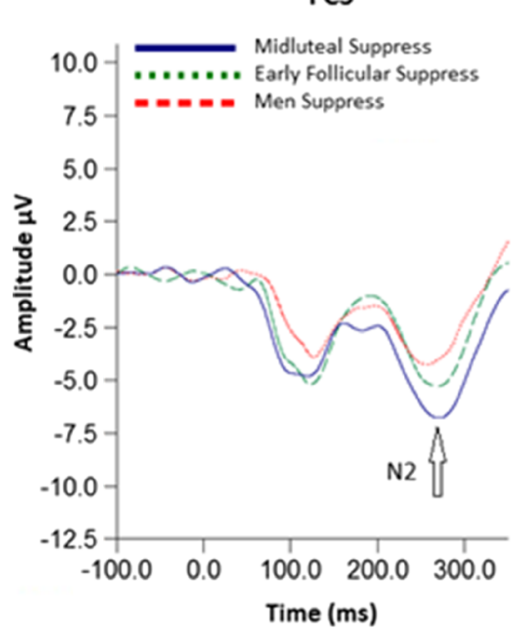

(b)

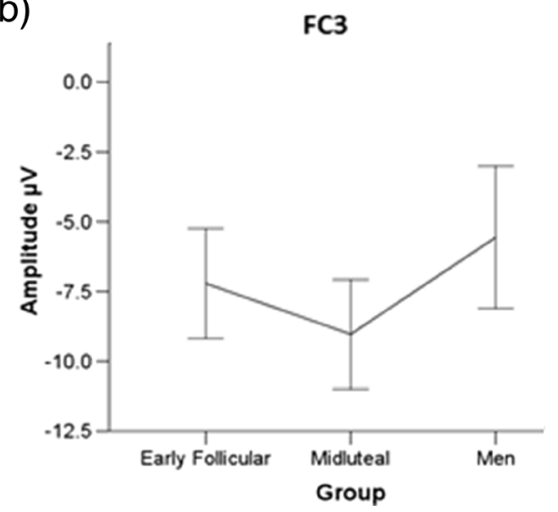

Fig. 4 As represented by a) the ERP waveform and b) $95 \%$ confidence intervals: the Group $\times$ Instruction interaction for N2 amplitude for early follicular, midluteal women, and men in response to "suppress" at FC3,

continued investigation of the impact of menstrual phase on visual emotion processing.

There was a significant group main effect for the N1 ERP component in the reappraisal block that showed that midluteal women had significantly greater N1 amplitudes than did men (see Fig. 2). This group effect was also present in the suppression block but only reached trend level (see Fig. 3). As N1 indexes early initial preconscious allocation of attention (Dong et al., 2011; Olofsson et al., 2008), these findings suggest that midluteal women display increased automatic activity in frontal attention networks compared to men. As the initial attentional response was to emotional stimuli, this increased early emotional reactivity in midluteal women is consistent with previous ERP studies reporting increased N1 to emotional stimuli in females (e.g., Gardener et al., 2013; Li et al., 2008; Lithari et al., 2010; Lusk et al., 2015).

\section{Early conscious attention: N2}

This study demonstrated a novel finding of a differential N2 amplitude response to suppression across menstrual phase. N2
FCZ

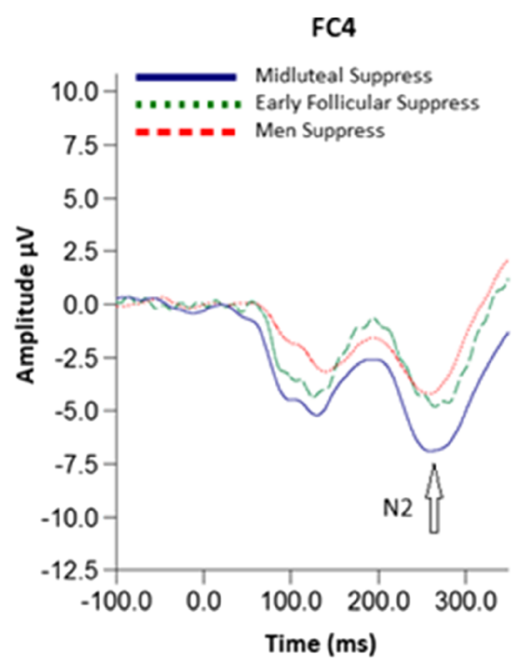

FC4

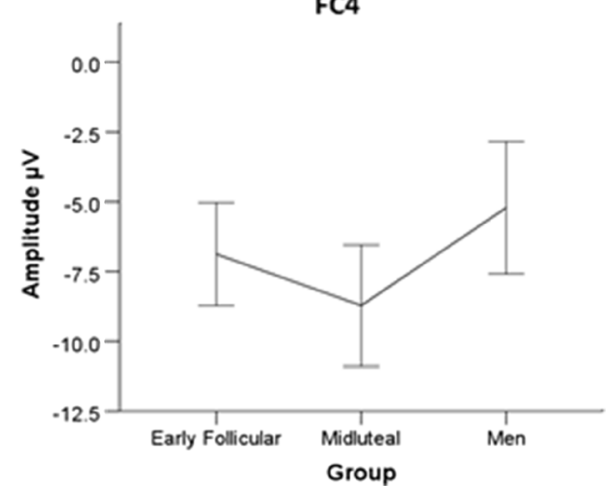

FCZ, and FC4 sites. Midluteal women were shown to have significantly greater N2 amplitude to the suppression instruction than men across all sites. (Color figure online)

activation was significantly increased during suppression of emotional response for midluteal women compared to men (see Fig. 3). Within visual processing paradigms, the N2 has been associated with selective attention and is thought to index early conscious allocation of attention to emotional stimuli (Anderson \& Stanford, 2012; Balconi \& Lucchiari, 2007; Patel \& Azzam, 2005; Schupp et al., 2006). The finding of increased N2 amplitude in midluteal women compared to men when suppressing emotional responses suggests that women in the midluteal phase have more cortical processing when consciously suppressing their emotional responses to unpleasant stimuli compared to men, which may be reflective of impaired suppression capacity. Supporting the obtained N2 interpretation, the correlational data demonstrated that progesterone was correlated with ERP amplitudes of the effects where we observed group differences. Specifically, a trendlevel significance relationship between increased progesterone levels, as observed during the midluteal phase, and increased N2 amplitude during suppression, but not reappraisal, was revealed. While only approaching significance, this finding suggests a direct role of progesterone in influencing the 
Table 3 Pearson's product-moment correlations between progesterone and either ERP component amplitudes, distress ratings, or effort ratings during reappraisal and suppression

\begin{tabular}{lll}
\hline Variable & $r$ & $p$ \\
\hline Reappraisal & & \\
P1 & .202 & .065 \\
$\mathrm{~N} 1$ & -.235 & .03 \\
$\mathrm{~N}$ & -.155 & .16 \\
Distress & .019 & .86 \\
Effort & -.064 & .56 \\
Suppression & & \\
P1 & .046 & .68 \\
N1 & -.232 & .03 \\
N2 & -.254 & .02 \\
Distress & .161 & .14 \\
Effort & .068 & .54 \\
\hline
\end{tabular}

Note: $N=84$ for all analyses, No significant correlations following Bonferroni correction; Boldface font $=$ trend-level significance correlation following Bonferroni correction. This trend-level finding indicated a relationship between progesterone and N2 amplitude signaling a role of progesterone upon the obtained group findings

obtained group and midluteal phase findings. The interpretation of decreased suppression capacity in midluteal women was further supported by the obtained behavioral rating data, where midluteal women reported significantly greater distress and effort levels than men during suppression. Interestingly, previous ERP literature has associated increased N2 amplitude with increased effort (e.g., go/no-go tasks; Benikos, Johnstone, \& Roodenrys, 2013).

The finding that midluteal women require greater cortical processing and effort and experience more distress when suppressing their emotional response compared to men converges with recent evidence from fMRI studies suggesting that men have superior and more efficient suppression ability than women (McRae et al., 2008). These consistent behavioral rating and N2 amplitude findings indicate that women, particularly midluteal women, may have a reduced capacity to suppress negative emotional processing. Subsequently, as deficits in emotion regulation capacity are functional markers of anxiety and depression (Cisler \& Koster, 2010; Farb et al., 2012), further research should investigate similarities in sex differences controlling for menstrual phase in clinical anxiety and depressive disorder populations.

\section{Conscious emotion regulation: P3 and LPP}

The only observed emotion regulation effect during late P3 processing was reduced P3 amplitude during suppression of emotional response, which might suggest that irrespective of group, suppression was an effective strategy to reduce late P3

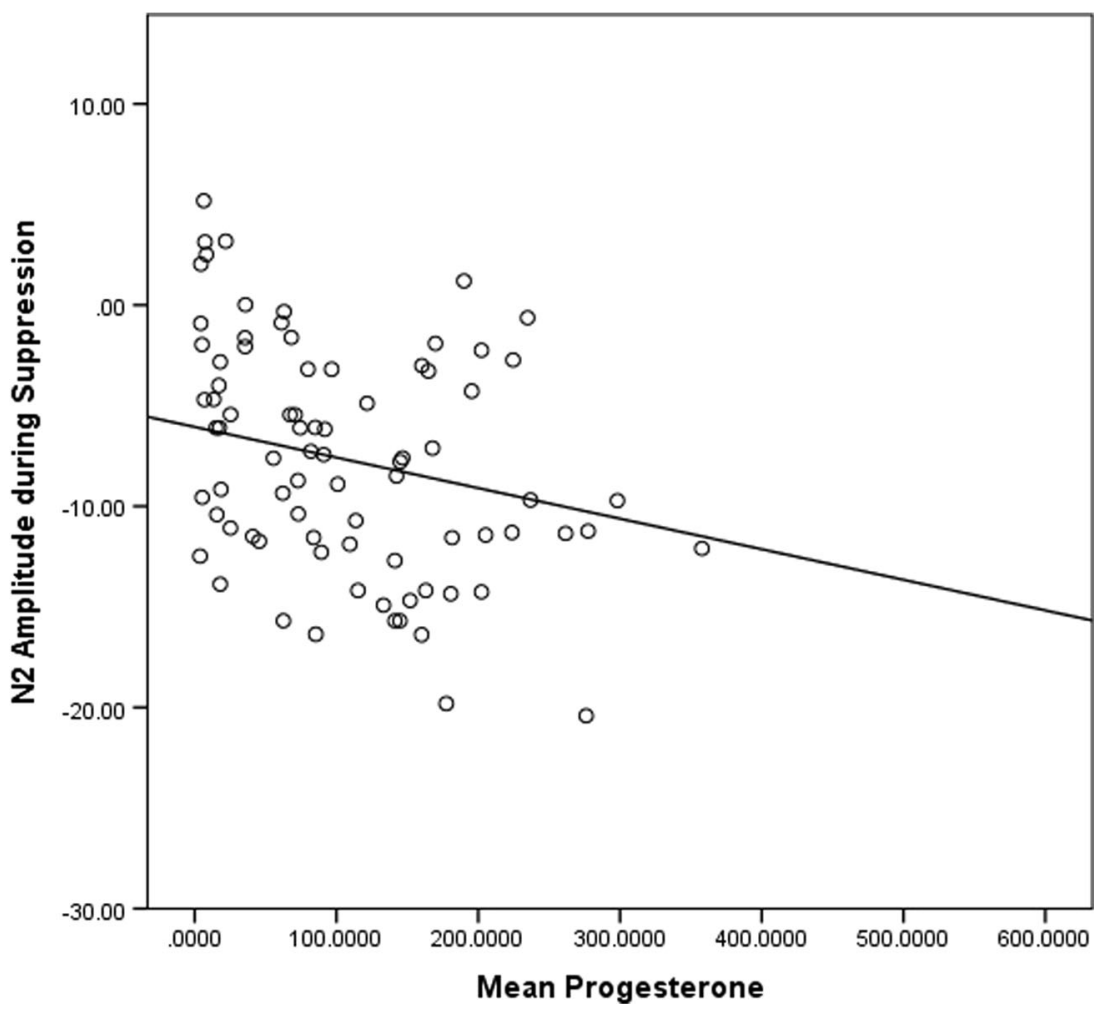

Fig. 5 Correlation between progesterone and N2 amplitude during suppression. Following Bonferroni adjustment, a trend-level significance negative correlation between progesterone and N2 amplitude during suppression signified a relationship between greater progesterone levels and increased N2 amplitude following suppression instruction 
Table 4 Pearson's product-moment correlations between ERP component amplitudes and distress and effort ratings during reappraisal and suppression

\begin{tabular}{lll}
\hline Variable & $r$ & $p$ \\
\hline Reappraisal-Distress & & \\
P1 & .070 & .53 \\
N1 & -.446 & $<.001$ \\
N2 & -.226 & .04 \\
Reappraisal-Effort & & \\
P1 & -.045 & .69 \\
N1 & -.249 & .02 \\
N2 & -.093 & .40 \\
Suppression-Distress & & \\
P1 & .045 & .68 \\
N1 & -1.66 & .13 \\
N2 & -.015 & .89 \\
Suppression-Effort & & .35 \\
P1 & .104 & .01 \\
N1 & -.269 & .47 \\
N2 & -.090 & \\
\hline
\end{tabular}

Note: $N=84$ for all analyses; Boldeface marked with $*=$ correlation significant following Bonferroni correction; boldface font $=$ trend-level significance correlation following Bonferroni correction. A significant correlation between distress level and N1amplitude was found during reappraisal while trend-level correlations between N1 amplitude and effort during reappraisal and suppression were demonstrated

cortical response to the unpleasant stimuli. While no effect of emotion regulation was found during the early 450-700-ms LPP time window, a significant emotion regulation effect was revealed in the late 1,000-3,000-ms LPP time window during reappraisal. This finding indicated that regardless of group, reappraisal was a useful regulation approach for decreasing late LPP cortical response. While menstrual phase modulation was found during early preconscious and early conscious processing, no sex or menstrual phase effects during late conscious emotional regulation processing were demonstrated in the current study.

The reappraisal effect during the late LPP time window replicates several studies that have examined emotion regulation instructions with ERPs to reveal an effect of emotion regulation instruction on the LPP (e.g., Hajcak \& Nieuwenhuis, 2006; Hajcak et al., 2010; Moser et al., 2010; Strauss et al., 2013; Wu et al., 2013). However, a suppression effect was not revealed during late LPP processing, and emotion regulation modulation of the LPP was not observed in the current study during the early time window. Methodological differences may have influenced the divergent findings given previous research has superimposed emotion regulation instructions over a cognitive task (e.g., Moser et al., 2010) or failed to examine menstrual phase (e.g., Hajcak \& Nieuwenhuis, 2006). Previous studies reporting an impact of menstrual phase on LPP amplitudes found inconsistent results, with some reporting increased LPP amplitude to sexual stimuli during the late follicular phase compared to early follicular and midluteal phases (Krug et al., 2000), and others reporting increased LPP amplitudes to all emotional and neutral stimuli in midluteal women compared to early follicular women (Zhang, Zhou, Wang, Zhao, \& Liu, 2013). To our knowledge, this is the only emotion regulation study to assess the impact of menstrual phase using ERPs, and consequently the comparison of the current study with previous literature is somewhat limited.

\section{Limitations and future research}

While this study addresses an important gap in the sex differences and emotion literature and reveals novel ERP evidence that suggests that midluteal women are less able to regulate their emotional response through suppression than are men, there are some limitations to this study. The current task was adapted from those of Goldin et al. (2008) and Moser et al. (2010) and thus reappraisal and suppression strategies were compared against their own baseline (maintain instruction), thereby restricting us from directly comparing the effects of reappraisal and suppression strategy on cortical activity. To minimize confounding of reappraisal and suppression, future emotion regulation research should include separate reappraisal, suppression, and maintain blocks to enable direct comparison. We analysed for potential baseline differences between the reappraisal and suppression maintain blocks for each ERP component and found that maintain (suppression) was higher than maintain (reappraisal) for N2 amplitude. However, no baseline differences involving group or sex were found. Given the few baseline differences and that the greater $\mathrm{N} 2$ amplitude for women than for men during suppression is in the opposite direction, this difference therefore did not inflate our findings.

We obtained behavioral data (distress and effort ratings) that supported the interpretation of the N2 effect in midluteal women, but we did not observe a relationship between progesterone and distress or effort ratings. However, it is quite common for a correlation not to be found between behavioral and ERP data (e.g., Albert, López-Martín, \& Carretié, 2010; Izurieta Hidalgo et al., 2016; Kappenman, Farrens, Luck, \& Hajcak Proudfit, 2014). While we did find a reappraisal effect during late LPP processing, overall we failed to replicate P3 and LPP modulation reported in previous emotion regulation studies (e.g., Hajcak \& Nieuwenhuis, 2006; Hajcak et al., 2010; Moser et al., 2010; Strauss et al., 2013; Wu et al., 2013). However, these studies did not examine menstrual phase, which may explain why emotion regulation effects were not found in the current study.

Due to restrictions on recruiting a longitudinal sample, we used a mixed-subjects design and collected a relatively small 
cross-sectional participant sample. While analyses were adequately powered, this may have resulted in an underestimation of differences between menstrual phases because of interindividual variability between groups. Future research would benefit from using a within-group design with a larger sample to assess women tested across their different menstrual phases to control for individual differences. The dates between which participant's subsequent menstruation following testing occurred were not collected in the current study. Future research should overcome this limitation by recording menstruation periods following experimental testing to provide additional confirmation of women's classification into menstrual cycle phases. Progesterone levels were within the expected range for early follicular and midluteal women (Healthscope Pathology, 2011), however, unfortunately, the estradiol data in this study could not be analyzed due to artefact (meaningless due to very low levels). While standardised storage and assay protocols were followed, data collection occurred over a 12-month period, which may have led to deterioration in saliva samples that impacted on estradiol values. Thus, we were unable to examine if the effects are due specifically to estradiol or progesterone. Future research should strive to collect blood samples for more reliable estimates of estradiol and examine the impact of estradiol and progesterone on ERPs, specifically.

\section{Conclusion}

Most previous emotion regulation studies have not investigated sex hormones or the impact of menstrual phase on emotion regulation processing. The current study provides novel evidence that menstrual phase may impact on cortical processing during suppression of negative emotional responses. Specifically, midluteal women revealed increased N2 amplitude following suppression instruction and reported greater distress levels and effort when suppressing compared to men, suggesting they have less capacity to suppress cortical processing of unpleasant stimuli relative to men. In addition, midluteal women reported greater early automatic attentional processing of negative emotional stimuli. This reduced capacity to suppress negative emotional processing in women may be a potential risk factor for developing anxiety and depressive disorders that are more prevalent in women, and the finding that this is particularly significant during the midluteal phase suggests that women may have heightened risk of emotional dysregulation in the later stages of their menstrual cycle. The current findings highlight the importance of considering menstrual phase in emotional neuroscience research when examining visual processing and emotion regulation. Future research should examine the relative impact of progesterone and estradiol in influencing these processes.
Acknowledgments We wish to thank Dr. Michael Quinn for assistance with statistical analysis and Associate Professor Nuri Guven for assistance with salivary analysis. We would like to thank Tessa Batt and Sara Forni Zervoudaki for assistance with data collection, and we also thank participants for their contribution to this study.

\section{Compliance with ethical standards}

Funding This work was supported by a National Health and Medical Research Council (NHMRC) Program Grant (APP1073041). The funding source had no further involvement in this study.

\section{Conflicts of interest None}

Contributors Bethany R. Lusk ${ }^{\mathrm{a}}$, Andrea R. Carr ${ }^{\mathrm{b}}$, Valerie A. Ranson ${ }^{\text {a }, \& \text { Kim L. Felmingham }}{ }^{\mathrm{c}}$

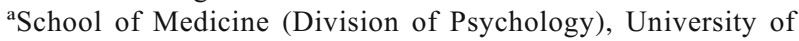
Tasmania, Private Bag 30, Hobart, Tasmania, 7001, Australia

${ }^{\mathrm{b}}$ Division of the Deputy Vice-Chancellor (Students and Education), University of Tasmania, Hobart, Tasmania, 7001, Australia

${ }^{\mathrm{c}}$ School of Psychological Sciences, University of Melbourne,

Melbourne, Victoria, 3010, Australia

Conceived and designed the experiment: B.L., A.C., K.F.

Performed the experiment: B.L., V.R., A.C., K.F.

Analyzed the data: B.L., A.C., K.F.

Contributed reagents/materials/analysis tools: B.L., K.F.

Wrote the paper: B.L., K.F.

\section{References}

Albert, J., López-Martín, S., \& Carretié, L. (2010). Emotional context modulates response inhibition: Neural and behavioral data. NeuroImage, 49, 914-921. doi:10.1016/j.neuroimage.2009.08.045

Anderson, N. E., \& Stanford, M. S. (2012). Demonstrating emotional processing differences in psychopathy using affective ERP modulation. Psychophysiology, 49, 792-806.

Andreano, J. M., \& Cahill, L. (2010). Menstrual cycle modulation of medial temporal activity evoked by negative emotion. NeuroImage, 53, 1286-1293.

Balconi, M., \& Lucchiari, C. (2007). Consciousness and emotional facial expression recognition: Subliminal/supraliminal stimulation effect on N200 and P300 ERPs. Journal of Psychophysiology, 21, 100108.

Becker, J. B., Arnold, A. P., Berkley, K. J., Blaustein, J. D., Eckel, L. A., Hampson, E.,...Young, E. (2005). Strategies and methods for research on sex differences in brain and behavior. Endocrinology, 146, 1650-1673. doi:10.1210/en.2004-1142

Benikos, N., Johnstone, S. J., \& Roodenrys, S. J. (2013). Varying task difficulty in the go/nogo task: The effects of inhibitory control, arousal, and perceived effort on ERP components. International Journal of Psychophysiology, 87, 262-272.

Bradley, M. M., \& Lang, P. J. (1994). Measuring emotion: The selfassessment manikin and the semantic differential. Journal of Behavior Therapy and Experimental Psychiatry, 25, 49-59.

Brot, M. D., Koob, G. F., \& Britton, K. T. (1995). Anxiolytic effects of steroid hormones during the estrous cycle interactions with ethanol. In M. Galanter (Ed.), Recent developments in alcoholism: Women and alcoholism (pp. 243-259). New York: Plenum Press.

Cisler, J. M., \& Koster, E. H. W. (2010). Mechanisms of attentional biases towards threat in anxiety disorders: An integrative review. Clinical Psychology Review, 30, 203-216. 
Cohen, J. (1988). Statistical power analysis for the behavior sciences. Mahwah: Erlbaum.

Compumedics Neuroscan. (2006). Edit 4.5. El Paso, TX: Author.

de Kloet, E. R., Joëls, M., \& Holsboer, F. (2005). Stress and the brain: From adaptation to disease. Nature Reviews Neuroscience, 6, 463 475.

Domes, G., Schulze, L., Bottger, M., Grossmann, A., Hauenstein, K., Wirtz, P. H.,...Herpertz, S. C. (2010). The neural correlates of sex differences in emotional reactivity and emotion regulation. Human Brain Mapping, 31, 758-769.

Dong, G. H., Zhou, H., Zhao, X. A., \& Lu, Q. L. (2011). Early negativity bias occurring prior to experiencing of emotion: An ERP study. Journal of Psychophysiology, 25, 9-17.

Etkin, A. (2009). Functional neuroanatomy of anxiety: A neural circuit perspective. Current Topics in Behavioral Neurosciences, 5, 1-27.

Fabiani, M., Gratton, G., \& Coles, M. G. H. (2000). Event-related potentials: Methods, theory and applications. In J. Cacioppo, L. Tassinary, \& G. Berntson (Eds.), Handbook of psychophysiology (2nd ed., pp. 53-84). New York: Cambridge University Press.

Farb, N. A. S., Anderson, A. K., \& Segal, Z. V. (2012). The mindful brain and emotion regulation in mood disorders. Canadian Journal of Psychiatry, 57, 70-77.

Gandara, B. K., Leresche, L., \& Mancl, L. (2007). Patterns of salivary estradiol and progesterone across the menstrual cycle. Annals of the New York Academy of Sciences, 1098, 446-450.

Gardener, E. K. T., Carr, A. R., Macgregor, A., \& Felmingham, K. L. (2013). Sex differences and emotion regulation: An event-related potentials study. PLoS ONE, 8, e73475.

Goldin, P. R., McRae, K., Ramel, W., \& Gross, J. J. (2008). The neural bases of emotion regulation: Reappraisal and suppression of negative emotion. Biological Psychiatry, 63, 577-586.

Goldstein, J. M., Jerram, M., Abbs, B., Whitefield-Gabrieli, S., \& Makris, N. (2010). Sex differences in stress response circuitry activation dependent on female hormone cycle. Journal of Neuroscience, 30, $431-438$.

Goldstein, J. M., Jerram, M., Poldrack, R., Ahern, T., Kennedy, D. N., Seidman, L. J.,...Makris, N. (2005). Hormonal cycle modulates arousal circuitry in women using functional magnetic resonance imaging. Journal of Neuroscience, 2540, 9309-9316.

Goldstein, J. M., Kennedy, D. N., \& Caviness, V. S. (1999). Images in neuroscience: Brain development: Sexual dimorphism. American Journal of Psychiatry, 156, 352.

Goldstein, J. M., Seidman, L. J., Horton, N. J., Makris, N., Kennedy, D. N., Caviness, V. S.,...Tsuang, M. T. (2001). Normal sexual dimorphism of the adult human brain assessed by in vivo magnetic resonance imaging. Cerebral Cortex, 11, 490-497.

Gross, J. J. (2007). Handbook of emotion regulation. New York: Guildford Press.

Gross, J. J., \& John, O. P. (2003). Individual differences in two emotion regulation processes: Implications for affect, relationships, and wellbeing. Journal of Personality and Social Psychology, 85, 348-362.

Gross, J. J., Sheppes, G., \& Urry, H. L. (2011). Cognition and emotion lecture at the 2010 SPSP emotion preconference. Cognition and Emotion, 25, 765-781.

Gross, J. J., \& Thompson, R. A. (2007). Emotion regulation: Conceptual foundations. In J. J. Gross (Ed.), Handbook of emotion regulation (pp. 3-26). New York: Guildford Press.

Guapo, V. G., Graeff, F. G., Zani, A. C. T., Labate, C. M., dos Reis, R. M., \& Del-Ben, C. M. (2009). Effects of sex hormonal levels and phases of the menstrual cycle in the processing of emotional faces. Psychoneuroendocrinology, 34, 1087-1094. doi:10.1016/j. psyneuen.2009.02.007

Hajcak, G., MacNamara, A., \& Olvet, D. M. (2010). Event-related potentials, emotion, and emotion regulation: An integrative review. Developmental Neuropsychology, 35, 129-155.
Hajcak, G., \& Nieuwenhuis, S. (2006). Reappraisal modulates the electrocortical response to unpleasant pictures. Cognitive, Affective, \& Behavioral Neuroscience, 6, 291-297.

Healthscope Pathology. (2011). Healthscope functional pathology practitioner manual (3rd ed). Australia: Healthscope.

Hillyard, S. A., \& Anllo-Vento, L. (1998). Event-related brain potentials in the study of visual selective attention. Proceedings of the National Academy of Sciences of the United States of America, 95, 781-787.

Hofmann, S. G., Sawyer, A. T., Fang, A., \& Asnaani, A. (2012). Emotion dysregulation model of mood and anxiety disorders. Depression and Anxiety, 29, 409-416.

Izurieta Hidalgo, N. A., Oelkers-Ax, R., Nagy, K., Mancke, F., Bohus, M., Herpertz, S. C., \& Bertsch, K. (2016). Time course of facial emotion processing in women with borderline personality disorder: An ERP study. The Japanese Journal of Psychiatry and Neurology, 41, 16-26. doi:10.1503/jpn.140215

Jasper, H. H. (1958). The 10-20 electrode system of the international federation. Electroencephalography and Clinical Neurophysiology, 10, 371-375.

Joffe, H., Hall, J. E., Gruber, S., Sarmiento, I. A., Cohen, L. S., YurgelunTodd, D., \& Martin, K. A. (2006). Estrogen therapy selectively enhances prefrontal cognitive processes: A randomized, doubleblind, placebo-controlled study with functional magnetic resonance imaging in perimenopausal and recently postmenopausal women. Menopause, 13, 411-422.

Kappenman, E. S., Farrens, J. L., Luck, S. J., \& Hajcak Proudfit, G. (2014). Behavioral and ERP measures of attentional bias to threat in the dot-probe task: Poor reliability and lack of correlation with anxiety. Frontiers in Psychology, 5, 1-9. doi:10.3389/fpsyg.2014. 01368

Kessler, R. C., Chiu, W. T., Demler, O., \& Walters, E. E. (2005). Prevalence, severity, and comorbidity of 12-Month DSM-IV disorders in the national comorbidity survey replication. Archives of General Psychiatry, 62, 617-709.

Kessler, R. C., Mcgonagle, K. A., Zhao, S. Y., Nelson, C. B., Hughes, M., Eshleman, S.,...Felmingham, K. L. (1994). Lifetime and 12-month prevalence of DSM-IV-R psychiatric disorders in the United States: Results from the national comorbidity survey. Archives of General Psychiatry, 51, 8-19.

Krug, R., Plihal, W., Fehm, H. L., \& Born, J. (2000). Selective influence of the menstrual cycle on perception of stimuli with reproductive significance: An event-related potential study. Psychophysiology, 37, 111-122.

Lang, P. J., Bradley, M. M., \& Cuthbert, B. N. (2008). International affective picture system (IAPS): Affective ratings of pictures and instruction manual (Technical report A-8). Gainesville: University of Florida.

Lebron-Milad, K., Abbs, B., Milad, M. R., Linnman, C., Rougemount-Bucking, A., Zeidan, M. A.,...Goldstein, J. M. (2012). Sex differences in the neurobiological of fear conditioning and extinction: A preliminary fMRI study of shared sex differences with stress-arousal circuitry. Biology of Mood \& Anxiety Disorders, 2, 1-10.

Lebron-Milad, K., \& Milad, M. R. (2012). Sex differences, gonadal hormones, and the fear extinction network: Implications for anxiety disorders. Biology of Mood \& Anxiety Disorders, 2, 1-12.

Li, H., Yuan, J. J., \& Lin, C. D. (2008). The neural mechanism underlying the female advantage in identifying negative emotions: An eventrelated potential study. NeuroImage, 40, 1921-1929.

Lithari, C., Frantzidis, C. A., Papadelis, C., Vivas, A. B., Klados, M. A., Kourtidou-Papadeli, C.,....Bamidis, P. D. (2010). Are females more responsive to emotional stimuli? A neurophysiological study across arousal and valence dimensions. Brain Topography, 23, 27-40.

Lovibond, P. F., \& Lovibond, S. H. (1995). The structure of negative emotional states: Comparison of the Depression Anxiety Stress 
Scales (DASS) with the Beck Depression and Anxiety Inventories. Advances in Behaviour Research and Therapy, 33, 345-353.

Luck, S. J., Woodman, G. F., \& Vogel, E. K. (2000). Event-related potential studies of attention. Trends in Cognitive Sciences, 4, 432440

Lusk, B. R., Carr, A. R., Ranson, V. A., Bryant, R. A., \& Felmingham, K. L. (2015). Early visual processing is enhanced in the midluteal phase of the menstrual cycle. Psychoneuroendocrinology, 62, 343-351.

Marshall, J. C. (2001). Hormonal regulation of the menstrual cycle and mechanisms of ovulation. In J. Leslie., J. De Groot., \& L. Jamenson (Eds.), Endocrinology (pp. 2073-2085). Philadelphia, PA: E. B. Saunders.

Martin, V. T., \& Behbehani, M. (2006). Ovarian hormones and migraine headache: Understanding mechanisms and pathogenesis (Part 2). Headache, 46, 365-386.

McLean, C. P., Asnaani, A., Litz, B. T., \& Hofmann, S. G. (2011). Gender differences in anxiety disorders: Prevalence, course of illness, comorbidity and burden of illness. Journal of Psychiatric Research, 45, 1027-1035.

McRae, K., Ochsner, K. N., Mauss, I. B., Gabrieli, J. J. D., \& Gross, J. J. (2008). Gender differences in emotion regulation: An fMRI study of cognitive reappraisal. Group Processes \& Intergroup Relations, 11, $143-162$.

Monsell, S. (2003). Task switching. Trends in Cognitive Sciences, 7, 134 140.

Montague, D., Weickert, C. S., Tomaskovic-Crook, E., Rothmond, D. A., Kleinman, J. E., \& Rubinow, D. R. (2008). Oestrogen receptor alpha localisation in the prefrontal cortex of three mammalian species. Journal of Neuroendocrinology, 20, 893-903.

Moser, J. S., Krompinger, J. W., Dietz, J., \& Simons, R. F. (2009). Electrophysiological correlates of decreasing and increasing emotional responses to unpleasant pictures. Psychophysiology, 46, 1727.

Moser, J. S., Most, S. B., \& Simons, R. F. (2010). Increasing negative emotion by reappraisal enhances subsequent cognitive control: A combined behavioural and electrophysiological study. Cognitive, Affective, \& Behavioral Neuroscience, 10, 195-207.

Nikas, G., \& Makrigiannakis, A. (2003). Endometrial pinopodes and uterine receptivity. Annals of the New York Academy of Sciences, 997, 120-123. doi:10.1196/annals. 1290.042

O'Reilly, M. A., Cunningham, C. L., Lawlor, B. A., Walsh, C. D., \& Rowan, M. J. (2004). The effect of the menstrual cycle on electrophysiological and behavioral measures of memory and mood. Psychophysiology, 41, 592-603.

Ochsner, K. N., \& Gross, J. J. (2005). The cognitive control of emotion. Trends in Cognitive Sciences, 9, 242-249.

Olofsson, J. K., Nordin, S., Sequiera, H., \& Polich, J. (2008). Affective picture processing: An integrative review of ERP findings. Biological Psychology, 77, 247-265.

Osborne, J. W., \& Overbay, A. (2004). The power of outliers (and why researchers should always check for them). Practical Assessment, Research \& Evaluation, 9, 1-12.

Patel, S. H., \& Azzam, P. N. (2005). Characterization of N200 and P300: Selected studies of the event related potential. International Journal of Medical Sciences, 2, 147-154.

Phillips, S. M., \& Sherwin, B. B. (1992). Variations in memory function and sex steroid hormones across the menstrual cycle. Psychoneuroendocrinology, 17, 497-506.

Polich, J. (2007). Updating P300: An integrative theory of P3a and P3b. Clinical Neurophysiology, 118, 2128-2148.

Price, J. L., \& Drevets, W. C. (2012). Neural circuits underlying the pathophysiology of mood disorders. Trends in Cognitive Sciences, 16, 61-71.

Protopopescu, X., Pan, H., Altemus, M., Tuescher, O., Polanecsky, M., McEwen, B.,...Stern, E. (2005). Orbitofrontal cortex activity related to emotional processing changes across the menstrual cycle.
Proceedings of the National Academy of Sciences of the United States of America, 102, 16060-16065.

Schupp, H. T., Flaisch, T., Stockburger, J., \& Junghofer, M. (2006). Emotion and attention: Event-related brain potential studies. Understanding Emotions, 156, 31-51.

Schuster, J., Karlsson, T., Karlstrom, P. O., Poromaa, I. S., \& Dahl, N. (2010). Down-regulation of progesterone receptor membrane component 1 (PGRMC1) in peripheral nucleated blood cells associated with premature ovarian failure (POF) and polycystic ovary syndrome (PCOS). Reproductive Biology and Endocrinology, 8, 1-6. doi:10.1186/1477-7827-8-58

Semlitsch, H. V., Anderer, P., Schuster, P., \& Presslich, O. (1986). A solution for reliable and valid reduction of ocular artifacts applied to the P300 ERP. Psychophysiology, 23, 695-703.

Shirtcliff, E. A., Granger, D. A., Schwartz, E., \& Curran, M. J. (2001). Use of salivary biomarkers in biobehavioral research: Cotton-based sample collection methods can interfere with salivary immunoassay results. Psychoneuroendocrinology, 26, 165-173.

Solis-Ortiz, S., \& Corsi-Cabrera, M. (2008). Sustained attention is favoured by progesterone during early luteal phase and visuospatial memory by estrogens during ovulatory phase in young women. Psychoneuroendocrinology, 33, 989-998.

Spencer, J. L., Waters, E. M., Romeo, R. D., Wood, G. E., Milner, T. A., \& McEwen, B. S. (2008). Uncovering the mechanisms of estrogen effects on hippocampal function. Frontiers in Neuroendocrinology, 29, 219-237.

Speroff, L., \& Fritz, M. A. (Eds.). (2010). Clinical gynecologic endocrinology and infertility (8th ed.). Philadelphia, PA: Wolters Kluwer/ Lippincott, Williams, \& Wilkins.

Strauss, G. P., Kappenman, E. S., Culbreth, A. J., Catalano, L. T., Lee, B. G., \& Gold, J. M. (2013). Emotion regulation abnormalities in schizophrenia: Cognitive change strategies fail to decrease the neural response to unpleasant Stimuli. Schizophrenia Bulletin, 39, 872883. doi:10.1093/schbul/sbs 186

Sunderstom-Poromaa, I., \& Gingnell, M. (2014). Menstrual cycle influence on cognitive function and emotion processing: From a reproductive perspective. Frontiers in Neuroscience, 8, 1-16. doi:10. 3389/fnins.2014.00380

Tabachnick, B. G., \& Fidell, L. S. (2013). Using multivariate statistics (6th ed.). Boston: Pearson/Allyn \& Bacon.

Toffoletto, S., Lanzenberger, R., Gingell, M., SunderstomPoromaa, S., \& Comasco, E. (2014). Emotional and cognitive functional imaging of estrogen and progesterone effects in the female human brain: A systematic review. Psychoneuroendocrinology, 50, 28-52.

van Wingen, G. A., van Broekhoven, F., Verkes, R. J., Petersson, K. M., Backstrom, T., Buitelaar, J. K., \& Fernandez, G. (2008). Progesterone selectively increases amygdala reactivity in women. Molecular Psychiatry, 133, 325-333.

Walf, A. A., \& Frye, C. A. (2006). A review and update of mechanisms of estrogen in the hippocampus and amygdala for anxiety and depression behavior. Neuropsychopharmacology, 31, $1097-1111$.

Wassell, J., Rogers, S., Felmingham, K. L., Bryant, R. A., \& Pearson, J. (2015). Sex hormones predict the sensory strength and vividness of mental imagery. Biological Psychology, 107, 61-68.

Wassell, J., Rogers, S., Felmingham, K. L., Pearson, J., \& Bryant, R. A. (2015). Progesterone and mental imagery interactively predict emotional memories. Psychoneuroendocrinology, 51, 1-10.

Waugh, C. E., Hamilton, J. P., Chen, M. C., Joormann, J., \& Gotlib, I. H. (2012). Neural temporal dynamics of stress in comorbid major depressive disorder and social anxiety disorder. Biology of Mood \& Anxiety Disorders, 2, 1-15.

Wijayanto, T., Tochihara, Y., Wijaya, A. R., \& Hermawati, S. (2009). Combined factors effect of menstrual cycle and background noise 
on visual inspection task performance: A simulation-based task. Journal of Physiological Anthropology, 28, 253-259.

Wu, H., Tang, P., Huang, X., Hu, X., \& Luo, Y. (2013). Differentiating electrophysiological response to decrease and increase negative emotion regulation. Chinese Science Bulletin, 58, 1543-1550. doi: 10.1007/s11434-013-5746-X

Wu, M., Zhou, R., \& Huang, Y. (2014a). Effects of menstrual cycle and neuroticism on female's emotion regulation. International Journal of Psychophysiology, 94, 351-357.

Wu, H., Chen, C., Cheng, D., Yang, S., Huang, R., Cacioppo, S., \& Luo, Y.-J. (2014b). The mediation effect of menstrual phase on negative emotion processing: Evidence from N2. Social Neuroscience, 9, 278-288.

Zhang, W., Zhou, R., Wang, Q., Zhao, Y., \& Liu, Y. (2013). Sensitivity of the late positive potentials evoked by emotional pictures to neuroticism during the menstrual cycle. Neuroscience Letters, 553, 7-12.

Zhang, W., Zhou, R., Wang, Q., Zhao, Y., \& Liu, Y. (2015). Progesterone mediates the late positive potentials evoked by affective pictures in high neuroticism females. Psychoneuroendocrinology, 59, 49-58.

Zhang, W., Zhou, R., \& Ye, M. (2013). Menstrual cycle modulation of the late positive potential evoked by emotional faces. Perceptual \& Motor Skills: Learning \& Memory, 116, 707-723. 